\title{
AN EXPLORATIVE STUDY TO ASSESS THE KNOWLEDGE OF PREGNANT WOMEN REGARDING ANAEMIA IN GOVERNMENT MATERNITY HOSPITAL UJJAIN (M.P.) \\ Dr.SangeetaTiwari ${ }^{1}$ Mrs Shushma Shukla ${ }^{2}$ \\ ${ }^{1}$ Professor Government college of Nursing Ujjain(M.P.)India \\ ${ }^{2}$ Associate Professor at Govt College of Nursing, Ujjain, MP \\ Corresponding Email: tiwarisangeeta94@,gmail.com, sushma.sihmc2011@.gmail.com.
}

\begin{abstract}
Introduction: There is strong relationship between diet during pregnancy and babies weight at birth, higher the protein,fat,and carbohydrate intake the bigger the baby. Maternal iron status definitely affects the level of the iron store of new-born. Different survey conducted in developing countries revealed that nearly 230 million women are suffering from nutritional anaemia and almost half of them belongs to reproductive age group and $2 / 3^{\text {rd }}$ of them are pregnant and lactating,

Material and Method: An exploratory research approach was used to assess the knowledge of pregnant women regarding Anaemia. This design was considered appropriate for the present study to assess the knowledge of pregnant women regarding Anaemia and its relationship with selected variables.

Result: the analysis of data revealed that 5\%of women had Excellent knowledge (>75\%) 5\% had below average knowledge $(<35 \%), 30 \%$ had average knowledge $(35-50 \%)$ and 60\% pregnant women had Good knowledge (51.74\%). Study also showed that there is significant association found between knowledge score of pregnant women regarding Anaemia and duration of marriage, source of information and degree of Anaemia (women with normal Haemoglobin level)

Conclusion: Study concluded that if women have knowledge regarding nutritious diet which has to be eaten during pregnancy then she herself would try to get rid of anaemia for safer childbirth and healthy baby.
\end{abstract}

Key words: Anaemia, Knowledge, Antenatal Mother, Iron Deficiency Anaemia, Pregnancy

\section{BACKGROUND OF STUDY-}

Growing foetus depends entirely on its mothers healthy body for all needs, however sometimes it can be a time of fear of suffering and death, in case women begins pregnancy with low or absent stores of iron because of previous pregnancy, poor intake, substance abuse, increased foetal demands of iron leads to iron deficiency anaemia. Iron deficiency Anaemia is the most common form of malnutrition in the world and is the eights leading cause of death in pregnant women in developing countries leading to low birth weight which is in turn as important risk factor for infant mortality.1

Anaemia in pregnancy has detrimental effects on maternal and child health and prevalence of anaemia during pregnancy is alarmingly high, in spite of the implementation of the national nutritional anaemia prophylaxis 
programme which provides iron and folic acid which are the essential nutrients lacking in their diet.

A cross sectional descriptive study conducted at Sri ManakulaVinayagar medical college hospital, Puducherry, India. Targeted estimation of haemoglobin levels in adolescent girls and women in reproductive age group, intensive counselling and motivation of pregnant women to consume Iron and folic acid and ensuring adequate supply to them, intensive de-worming, provision of toilet facilities to all households would help in reducing the incidence of anaemia in pregnant women . $^{2}$

An analytical cross-sectional study involving 400 pregnant women receiving antenatal care in Tamale Teaching Hospital was conducted. Using a semistructured questionnaire and 24-h dietary recall, data were collected on sociodemographic characteristics, health practices, dietary diversity, and anaemia knowledge and haemoglobin level of the women. Anaemia was defined as haemoglobin concentration less than $11 \mathrm{~g} / \mathrm{dl}$. Chi-square test and logistic regression analysis were used to identify the independent determinants of pregnancy anaemia. The mean age and haemoglobin of the women were $28.3( \pm 4.5)$ years and $10.81( \pm 1.41) \mathrm{g} / \mathrm{dl}$ respectively. About half of the women 50.8\% [95\% Confidence
Interval (CI): 45.8-55.7] were anaemic and the prevalence of anaemia increased with pregnancy trimester. Among a host of socio-demographic, dietary, and preventive health service factors evaluated, the women's knowledge on anaemia and pregnancy trimester at interview were the independent determinants of anaemia in pregnancy. Compared to women of the highest anaemia knowledge score, women belonging to the lowest $(\mathrm{AOR}=2.63,95 \%$ CI: $1.50-4.61)$ and middle $(\mathrm{AOR}=1.92$, 95\% CI: 1.12-3.27) anaemia knowledge score were about 3 and 2 times more likely to be anaemic respectively. Similarly, women in third trimester of pregnancy were about 4 times more likely to be anaemic compared to those in first trimester at the time of interview $(\mathrm{AOR}=3.57, \quad 95 \% \quad \mathrm{CI}: \quad 1.91-6.67)$. The women's knowledge on anaemia and pregnancy trimester at the time of interview is associated with their anaemia status. The high prevalence of anaemia in pregnancy needs urgent intervention to prevent the occurrence of adverse maternal and neonatal outcomes. Education on anaemia should be intensified at ANCs.3

Anaemia is one of the most common nutritional deficiency disorders affecting the pregnant women in the developing countries. Anaemia during pregnancy is commonly associated with poor pregnancy outcome and can result in 
complications that threaten the life of both mother and fetus.so a prospective, observational, community-based study was conducted at three primary health centres in Kolar district by multistage sampling technique and were followed up till 1 week after delivery to estimate the prevalence of anaemia among pregnant women and to determine its association with maternal and foetal outcomes. They found that there was a significant overall improvement in the haemoglobin levels of pregnant during the follow-up (10.3-10.72 gm. \%). About $35.6 \%$ of the women had maternal or foetal morbidity. Anaemia was one of the main pregnancy-related complications $(62.3 \%)$, other complications include difficult labour (3\%), postpartum haemorrhage, and preeclampsia $1.6 \%$ each abortions/stillbirths (3.5\%). The foetal complications include low birth weight $(25.5 \%)$ followed by premature delivery $(0.2 \%)$ and birth asphyxia (0.5\%). The study concluded that a high prevalence of anaemia in pregnant women apparently increases the maternal and foetal risks.4

The prevalence of anaemia was observed to be $33.9 \%$; proportion of mild and moderate anaemia was almost similar

(48.4 and 49.5\%). The mean haemoglobin level of all the participants was $11.33 \pm 1.460 \mathrm{~g} / \mathrm{dl}$. The mean haemoglobin level concentration was high during early gestation with a slight decrease by $21-24$ weeks. 5

\section{Need for study}

Anaemia during pregnancy is a major public health problem in developing countries. It is important to regularly monitor haemoglobin level in pregnancy and factors associated with it to inform clinical and preventive services.

National Nutrition Mission has been setup under the oversight of the Ministry of Women and Child Development with the aim to reduce anaemia among young children, adolescent girls and women of reproductive age (1549 years) by one third of NFHS-4 levels by 2022.6

Pregnant Women Age 15 to 49 Who Are Anaemic (2015 - 2016) in India

\begin{tabular}{|l|l|l|}
\hline 1 & Rural & $52.1 \%$ \\
\hline 2 & Urban & $45.7 \%$ \\
\hline 3 & Total & $50.3 \%$ \\
\hline
\end{tabular}

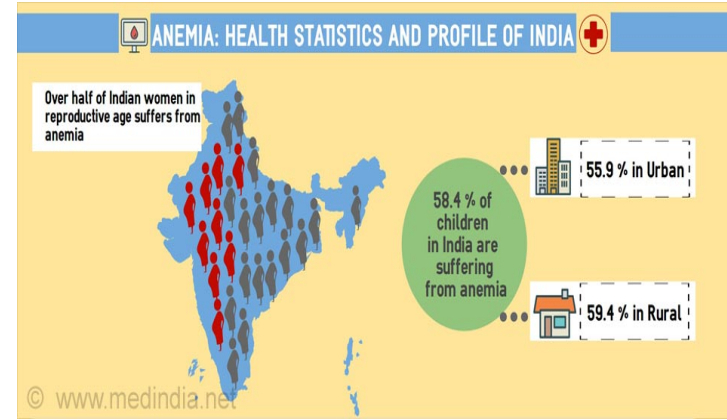

National Family Health Survey - 4: 2015 to 2016 


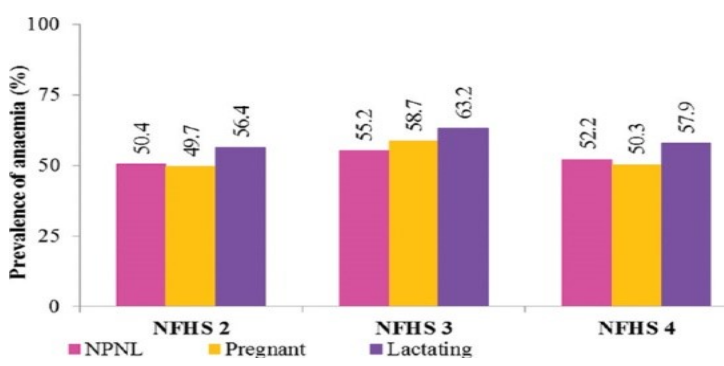

Report of Indian journal of medical research

Problem statement

An exploratory study to assess the

knowledge of pregnant women regarding

Anaemia in government maternity hospital

Ujjain(M.P.)

\section{Objective of study}

1) To assess the knowledge of pregnant women regarding Anaemia.

2) To identify the deficit areas of knowledge of pregnant women regarding anaemia.

3) To identify the relationship of knowledge of pregnant women with selected demographic variables.

4) To prepare guidelines on prevention of anaemia for pregnant women.

Assumption: Pregnant women do have knowledge related to anaemia and may be influenced by socio demographic variables.

Research Methodology: Quantitative research approach with exploratory research design were used

Setting of study: Government maternity Hospital Ujjain (M.P.)

Population: Pregnant women attending the antenatal outpatient department of government

maternity

hospital

Ujjain(M.P.)

Sample: Women who are pregnant

Sampling criteria: Purposive sampling

Sample size: 100

Tools and Technique: Semi structured questionnaire -total 34 question prepared related to knowledge on Anaemia.

A Semi structured questionnaire schedule -It was developed by researcher after reviewing the related literature and with suggestions and guidance from expert in the field of obstetric .and nutritionists.

\section{The Questionnaire Consist of two parts}

Part 1-Obtaining personal information about respondents. This part consist of 12 selected variables i.e. age, duration of marriage, educational status, occupation, type of family, family income, dietary habits, gravida, trimester, number of meal taking per day, source of information and degree of anaemia.

Part 2- This part of tool consist of 34 items related to definition of anaemia, physiology, cause, signs and symptoms, investigations, complication $\&$ prevention and control of anaemia.

\section{Scoring of the items is}

\begin{tabular}{|l|l|l|c|}
\hline $\begin{array}{l}\text { S } \\
\text { no }\end{array}$ & Grade & percentage & marks \\
\hline 1 & Excellent & $>75 \%$ & $>26$ \\
\hline 2 & Good & $51 \%-74 \%$ & $18-25$ \\
\hline 3 & Average & $35 \%-50 \%$ & $12-17$ \\
\hline 4 & $\begin{array}{l}\text { Below } \\
\text { Average }\end{array}$ & $<35 \%$ & $<12$ \\
\hline
\end{tabular}


Validity: Prepared tool is given to Experts for obtaining validity. According to their suggestion tools were modified.

Reliability: Reliability of tool was computed by split half technique and by using Spearman's Brown Prophecy formula. The reliability of knowledge tool was $\mathrm{r}=0.76$ so tool was reliable.

Ethical consideration: The written authorization to bring out the study was obtained by Chief Medical and Health Officer Ujjain. The data was collected from the participants were selected by purposive sampling. The reason of the study was explained to them and written informed consent was obtained. Confidentiality was assured to all subjects. They were informed about their right to refuse participation or withdraw at any time.

\section{METHODS OF DATA COLLECTION}

After obtaining permission from hospital authority Antenatal mothers were selected as per inclusion criteria. The purpose of the study was explained to the pregnant women and written and informed consent obtained. The participants were assured that the information provided by them will be kept confidential. The knowledge of pregnant women was assessed with the help of semi structured knowledge questionnaire. Maximum time taken by each participant was 20-30 minutes and afterward 3-5 minutes were utilizes to provide verbal guideline to the respondent by the investigator about Anaemia its symptom's causes and prevention.

\section{RESULTS:}

Baseline characteristics of pregnant women. Most of the pregnant mother $(60 \%)$ was in age group of $<20-25$ years. As regards to years of marriage $(70 \%)$ of pregnant women were 0-5 years and. Regarding educational status maximum (69\%)of pregnant women are graduate. According occupational status most of the pregnant mother (55\%) were Housewife. About types of family (55\%) lives in joint family. As per monthly income is concerned $(40 \%)$ pregnant women belongs to (10000-20000) groups. Regarding dietary habits $(70 \%)$ women belong to vegetarian group.(55\%) pregnant women were primigravida.(45\%) pregnant women in $3^{\text {rd }}$ trimester and (55\%) pregnant women taking meal 3 times daily. Regarding source of information (40\%) pregnant women receive information from mass media and(55\%) pregnant women had mild anaemia.

Table-1Distribution of pregnant mother according to their baseline characteristics. 


\begin{tabular}{|c|c|c|c|}
\hline $\begin{array}{l}\text { S } \\
\text { no }\end{array}$ & characteristics & number & percentage \\
\hline 1 & \multicolumn{3}{|l|}{ Age (years) } \\
\hline & $20-25$ & 60 & $60 \%$ \\
\hline & $26-30$ & 32 & $32 \%$ \\
\hline & $31-35$ & 8 & $8 \%$ \\
\hline & $36-40$ & - & - \\
\hline \multirow[t]{6}{*}{2} & \multicolumn{3}{|l|}{ Duration of marriage (years) } \\
\hline & $0-5$ & 70 & $70 \%$ \\
\hline & $6-10$ & 25 & $25 \%$ \\
\hline & $11-15$ & 5 & $5 \%$ \\
\hline & $16-20$ & - & - \\
\hline & $>^{20}$ & - & - \\
\hline \multirow[t]{5}{*}{3} & \multicolumn{3}{|l|}{ Educational Status } \\
\hline & illiterate & - & - \\
\hline & Primary & 6 & $6 \%$ \\
\hline & Higher Secondary & 25 & $25 \%$ \\
\hline & Graduate and above & 69 & $69 \%$ \\
\hline \multirow[t]{4}{*}{4} & \multicolumn{3}{|l|}{ Occupation } \\
\hline & Professional & 20 & $20 \%$ \\
\hline & Self employed & 25 & $25 \%$ \\
\hline & House Wife & 55 & $55 \%$ \\
\hline \multirow[t]{4}{*}{5} & \multicolumn{3}{|l|}{ Type of Family } \\
\hline & Joint & 55 & $55 \%$ \\
\hline & Nuclear & 42 & $42 \%$ \\
\hline & Extended & 3 & $3 \%$ \\
\hline \multirow[t]{4}{*}{6} & \multicolumn{3}{|l|}{ Family Income } \\
\hline & $<^{10000}$ & 35 & $35 \%$ \\
\hline & $10000-20000$ & 40 & $40 \%$ \\
\hline & $>^{20000}$ & 25 & $25 \%$ \\
\hline \multirow[t]{3}{*}{7} & \multicolumn{3}{|l|}{ Dietary Habit } \\
\hline & Vegetarian & 70 & $70 \%$ \\
\hline & Non Vegetarian & 30 & $30 \%$ \\
\hline \multirow[t]{3}{*}{8} & \multicolumn{3}{|l|}{ Gravida } \\
\hline & Primigravida & 55 & $55 \%$ \\
\hline & Multigravida & 45 & $45 \%$ \\
\hline \multirow[t]{4}{*}{9} & \multicolumn{3}{|l|}{ Trimester } \\
\hline & Tst & 25 & $25 \%$ \\
\hline & 2nd & 35 & $35 \%$ \\
\hline & 3rd & 40 & $40 \%$ \\
\hline \multirow[t]{4}{*}{10} & \multicolumn{3}{|l|}{ No of Meals taking per day } \\
\hline & Once & - & - \\
\hline & Twice & 35 & $35 \%$ \\
\hline & Thrice and More & 65 & $65 \%$ \\
\hline \multirow[t]{4}{*}{11} & \multicolumn{3}{|l|}{ Source of information } \\
\hline & Mass Media & 40 & $40 \%$ \\
\hline & Relative & 22 & $22 \%$ \\
\hline & Health Worker & 38 & $38 \%$ \\
\hline 12 & Degree of Anaemia & & \\
\hline & $\operatorname{Normal}(\mathrm{Hb}=\geq 10-12 \mathrm{gm} / \mathrm{dl})$ & 36 & $36 \%$ \\
\hline & Mild $(\mathrm{Hb}=8.1-10 \mathrm{gm} / \mathrm{dl})$ & 55 & $55 \%$ \\
\hline & Moderate $(\mathrm{Hb}=6.1-8 \mathrm{gm} / \mathrm{dl})$ & 9 & $9 \%$ \\
\hline & Severe $\left(\mathrm{Hb}=\leq^{6.0 \mathrm{gm} / \mathrm{dl})}\right.$ & - & - \\
\hline
\end{tabular}

Table-2 Comparative Mean Percentage According to Area and Total Knowledge score of Pregnant Women Regarding

\section{Anaemia}

\begin{tabular}{|l|l|l|l|l|l|}
\hline $\begin{array}{l}\text { Area of } \\
\text { Anaemia }\end{array}$ & $\begin{array}{l}\text { Max. } \\
\text { Score }\end{array}$ & $\begin{array}{l}\text { Mean } \\
\text { score }\end{array}$ & Mean \% & SD & Rank \\
\hline introduction & 4 & 3.03 & 75.7 & 1 & 1 \\
\hline Physiology & 5 & 1.93 & 38.6 & 1.08 & 6 \\
\hline Cause & 7 & 4.57 & 65.2 & 1.44 & 3 \\
\hline Investigation & 2 & 1.34 & 67 & .62 & 2 \\
\hline Complications & 4 & 2.12 & 53 & .99 & 4 \\
\hline $\begin{array}{l}\text { Prevention \& } \\
\text { control }\end{array}$ & 12 & 6.04 & 50.33 & 1.95 & 5 \\
\hline $\begin{array}{l}\text { Over all knowledge } \\
\text { score }\end{array}$ & 34 & 19.12 & 56.23 & 4.43 & \\
\hline
\end{tabular}

Above table depicts the mean and mean percentage of knowledge score of pregnant women regarding anaemia and rank order of areas in anaemia. Mean knowledge score of pregnant women regarding introduction was 3.03 followed by mean regarding Physiology 1.93. Investigation is 1.34, Cause and symptoms are 4.57, complications is 2.12 , and control and prevention is 6.04 .

Figure-1knowledge score of pregnant women regarding area of Anaemia

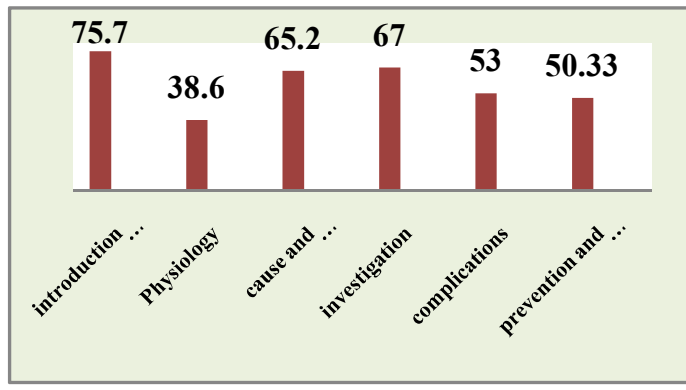

Hence deficit area regarding anaemia have been identified i.e. Most of the pregnant women were having knowledge introduction and definition of anaemia but less knowledge regarding prevention and control followed by least knowledge of its physiology.

Figure-2 Percentage distribution of level of knowledge of pregnant women regarding Anaemia 


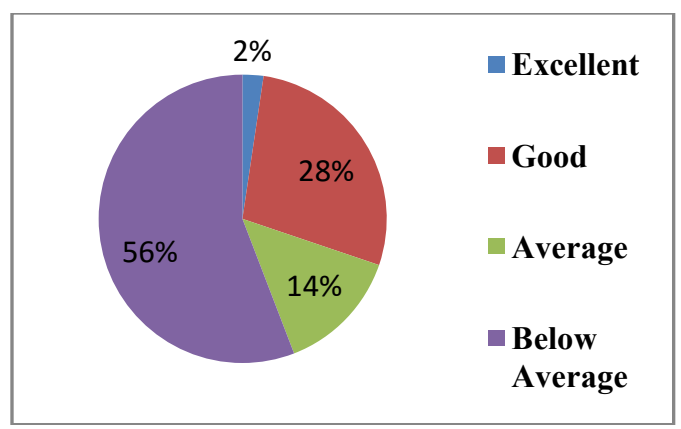

Figure 2 shows the percentage distribution of level of knowledge of pregnant women regarding Anaemia.2\% women obtained excellent score (>75\%),28\% women got good score(51-74), 56\% had below average knowledge score and 14\% had Average knowledge score regarding anaemia.

Table-3 Relationship of knowledge of pregnant women regarding anaemia with selected demographic variables.

Table 3 revealed the relationship of knowledge of pregnant women regarding anaemia with selected demographic variables.

This shows the significant relationship with age in years (20-25) and (31-35) ,duration of marriage (0-5years), source of information (health worker) and degree of anaemia (Hb level >10-12gm./dl).

The analysis also indicate that there is no significant relationship between age, (2630 years),duration of marriage(After 6years to 15 years),educational statue, occupation, family income, Dietary habit, gravida, trimester, no of meals per day, source of income(mass media, relatives), and degree of anaemia(Mild, Moderate) with the knowledge of pregnant women on anaemia.

\begin{tabular}{|c|c|c|c|c|c|}
\hline $\mathrm{Sn}$ & characteristics & No & $\%$ & SD & $\bar{Z}$ \\
\hline \multirow[t]{4}{*}{1} & \multicolumn{3}{|l|}{ Age (years) } & & \\
\hline & $20-25$ & 60 & $60 \%$ & 4.18 & $3.4(\mathrm{~S})$ \\
\hline & $26-30$ & 32 & $32 \%$ & 3.72 & $0.07(\mathrm{NS})$ \\
\hline & $31-35$ & 8 & $8 \%$ & 3.02 & $2.65(\mathrm{~S})$ \\
\hline \multirow[t]{4}{*}{2} & \multicolumn{3}{|c|}{ Duration of marriage (years) } & & \\
\hline & $0-5$ & 70 & $70 \%$ & 4.02 & 3.1(S) \\
\hline & $6-10$ & 25 & $25 \%$ & 3.21 & $0.34(\mathrm{NS})$ \\
\hline & $11-15$ & 5 & $5 \%$ & 2.32 & $1.06(\mathrm{NS})$ \\
\hline \multirow[t]{4}{*}{3} & \multicolumn{3}{|l|}{ Educational Status } & & \\
\hline & Primary & 6 & $6 \%$ & 2.33 & 1.34(NS) \\
\hline & Higher Secondary & 25 & $25 \%$ & 3.65 & $1.60(\mathrm{NS})$ \\
\hline & Graduate and above & 69 & $69 \%$ & 4.32 & $.53(\mathrm{NS})$ \\
\hline \multirow[t]{4}{*}{4} & \multicolumn{3}{|l|}{ Occupation } & & \\
\hline & Professional & 20 & $20 \%$ & 4.35 & $0.48(\mathrm{NS})$ \\
\hline & Self employed & 25 & $25 \%$ & 4.23 & $0.33(\mathrm{NS})$ \\
\hline & House Wife & 55 & $55 \%$ & 3.66 & $0.78(\mathrm{NS})$ \\
\hline \multirow[t]{4}{*}{5} & \multicolumn{3}{|l|}{ Type of Family } & & \\
\hline & Joint & 55 & $55 \%$ & 3.99 & $0.39(\mathrm{NS})$ \\
\hline & Nuclear & 42 & $42 \%$ & 3.85 & $0.98(\mathrm{NS})$ \\
\hline & Extended & 3 & $3 \%$ & 3.45 & $0.43(\mathrm{NS})$ \\
\hline \multirow[t]{4}{*}{6} & Family Income & & & & \\
\hline & $<^{10000}$ & 35 & $35 \%$ & $\mathbf{3 . 3 3}$ & $1.35(\mathrm{NS})$ \\
\hline & $10000-20000$ & 40 & $40 \%$ & 4.56 & $0.64(\mathrm{NS})$ \\
\hline & $>^{20000}$ & 25 & $25 \%$ & 5.89 & $1.82(\mathrm{NS})$ \\
\hline \multirow[t]{3}{*}{7} & Dietary Habit & & & & \\
\hline & Vegetarian & 70 & $70 \%$ & 4.65 & $1.38(\mathrm{NS})$ \\
\hline & Non Vegetarian & 30 & $30 \%$ & 3.95 & $1.20(\mathrm{NS})$ \\
\hline \multirow[t]{3}{*}{8} & Gravida & & & & \\
\hline & Primigravida & 55 & $55 \%$ & 4.65 & $0.66(\mathrm{NS})$ \\
\hline & Multigravida & 45 & $45 \%$ & 3.48 & $0.85(\mathrm{NS})$ \\
\hline \multirow[t]{4}{*}{9} & Trimester & & & & \\
\hline & 1st & 25 & $25 \%$ & 3.55 & $0.08(\mathrm{NS})$ \\
\hline & 2nd & 35 & $35 \%$ & 4.58 & 0.89 (NS) \\
\hline & 3rd & 40 & $40 \%$ & 4.32 & $0.95(\mathrm{NS})$ \\
\hline \multirow[t]{3}{*}{10} & \multicolumn{5}{|l|}{ No of Meals taking per day } \\
\hline & Twice & 35 & $35 \%$ & 3.22 & $1.34(\mathrm{NS})$ \\
\hline & Thrice and More & 65 & $65 \%$ & 4.56 & $1.29(\mathrm{NS})$ \\
\hline \multirow[t]{4}{*}{11} & \multicolumn{5}{|l|}{ Source of information } \\
\hline & Mass Media & 40 & $40 \%$ & 3.59 & $0.83(\mathrm{NS})$ \\
\hline & Relative & 22 & $22 \%$ & 4.12 & $1.56(\mathrm{NS})$ \\
\hline & Health Worker & 38 & $38 \%$ & 4.23 & $2.44(\mathrm{~S})$ \\
\hline \multirow[t]{4}{*}{12} & \multicolumn{5}{|l|}{ Degree of Anaemia } \\
\hline & $\begin{array}{l}\text { Normal(Hb= }=10-12 \\
\mathrm{gm} / \mathrm{dl})\end{array}$ & 36 & $36 \%$ & 4.35 & $2.55(\mathrm{~S})$ \\
\hline & Mild $(\mathrm{Hb}=8.1-10 \mathrm{gm} / \mathrm{dl})$ & 55 & $55 \%$ & 4.33 & $0.523(\mathrm{Ns}$ \\
\hline & $\begin{array}{l}\text { Moderate }(\mathrm{Hb}=6.1-8 \\
\mathrm{gm} / \mathrm{dl})\end{array}$ & 9 & $9 \%$ & 3.12 & 0.49 (NS) \\
\hline
\end{tabular}




\section{DISCUSSION}

Study revealed that most of the pregnant women $(60 \%)$ are at the age of 20-25 years which shows the significant association with knowledge regarding anaemia. Study also shows that $70 \%$ pregnant women who are having a history of 5 years duration of marriage are also having a significant knowledge regarding anaemia.

Its result revealed that most of the pregnant women $(70 \%)$ are at the age under 25 years, and (65\%) pregnant women are having a history of duration of marriage is under the 5 years, and both group indicate highly significant relationship with knowledge regarding anaemia.

\section{REFERENCE}

1) Ashly Baby et.al; knowledge of management of anaemia during Pregnancy; A descriptive study; AMHS:2014; volume2;Issue 2:P.P. 140-144.

2) Nivedita K., Fatima Sh anthi ni $N$. ; Knowledge, attitude and practices of pregnant women regarding anaemia, iron rich diet and iron supplement; international journal of reproduction contraception obstetrics and gynaecology; 0volume (5) 2016 DOI: http://dx.doi.org/10.18203/23201770.ijrcog20 $\underline{160383}$
3) Anthony Wemakor; Prevalence and determinants of anaemia in pregnant women receiving antenatal care at a tertiary referral hospital in Northern Ghana;BMC Pregnancy and Childbirth volume 19, Article number: 495 (2019)

4) RavishankarSuryanarayana et.al. Pros pective study on prevalence of anaemia of pregnant women and its outcome: A community based study; journal of primary medicine nd primary care;2017 Oct-Dec; 6(4): 739-743.

5) J Vindhya ${ }^{1}$, Anita Nath $^{1}, G \quad$ V. S. Murthy $^{2}$, Chandra Metgud ${ }^{3}$, B Sheeba $^{1}, \mathrm{~V}$ Shubhashree ${ }^{1}, \mathrm{P}$ SrinivasPrevalence and risk factors of anemia among pregnant women attending a public-sector hospital in Bangalore, South India; journal of family medicine and primary careYear :2019; Volume :8 Issue :1 Page : $37-43$

6) Dr. arunarastogi;published date : oct 23, 2018published by : NHP admin.created / validated by apps.who.int/iris/bitstream/handle/10665/77 770/9789241501996.

7) Anemia: Health Statistics and Profile of IndiaCompiled by ChrisyNgilneii, B.Sc (Psychology), M.A (Sociology), Ph.D. (Epidemiology)Reviewedby the MedIndia Review Team on Nov 22, 2017 